\section{Consumer Preferences for Longevity Information and Guarantees on Cut Flower Arrangements}

\author{
Alicia L. Rihn ${ }^{1,5}$ \\ Department of Horticulture Science, University of Minnesota, 1970 Folwell \\ Avenue, St. Paul, MN 55108
}

Chengyan Yue ${ }^{2}$

Departments of Horticulture Science and Applied Economics, University of Minnesota, 1970 Folwell Avenue, St. Paul, MN 55108

Charles Hall ${ }^{3}$

Department of Horticultural Sciences, Texas A\&M University, 202 Horticulture Forest Science Building, College Station, TX 77843-2133

Bridget K. Behe ${ }^{4}$

Department of Horticulture, Michigan State University, 1066 Bogue Street, East Lansing, MI 48824

Additional index words. Antirrhinum majus, Chamelaucium uncinatum Shauer, choice experiments, Gloriosa superb, Gyposphila paniculata, Rosa $\times$ hybrida, Tulipa

Abstract. Choice experiments were conducted to explore the market potential or value added when using longevity information and guarantees on cut flower arrangements in the retail setting. The objective of our study was to determine consumer preferences and willingness to pay for different vase life longevities and guarantees on cut flower arrangements. The choice experiment data were collected using online surveys with 525 U.S. consumers in July 2011. The choice experiment scenarios included single species or mixed species cut flower arrangements with varying vase life longevity ( 5 to 7 days, 8 to 10 days, 11 to 14 days), presence or absence of vase life longevity guarantee, personal or gift use, and price range (\$7.99 to $\$ 11.99, \$ 34.99$ to $\$ 43.99)$. Two types of arrangements were used in the experiment, mixed arrangements consisting of different species of cut flowers and single-species arrangements consisting of six red roses plus a filler flower. We analyzed the data with a mixed logit model and Ward's linkage cluster analysis. As expected, participants were willing to pay higher prices for cut flower arrangements with longer vase life longevity. The presence of a guarantee improved participants' probability of selecting the corresponding cut flower arrangement. Using Ward's linkage cluster analysis, we found there were three distinct consumer clusters: guarantee seekers (49\% of the sample), value-conscious consumers (31\%), and spenders $(20 \%)$. Among the three clusters, guarantee seekers were more likely to select cut flower arrangements with guarantees. Value-conscious consumers were interested in both guarantees and longevity indicators. Spenders were least interested in longevity indicators and guarantees. We conclude floral retailers could successfully implement the use of longevity indicators and guarantees to increase consumer interest in cut flowers and generate profits. Target marketing strategies could then be developed by floral retailers to attract different consumer clusters.

Fresh-cut flowers have been an important part of our society since ancient Greece and continue to be enjoyed for their aesthetics on numerous holidays, as gifts, and on other

Received for publication 27 Jan. 2014. Accepted for publication 17 Apr. 2014.

We gratefully acknowledge funding from the American Floral Endowment (AFE)

${ }^{1} \mathrm{Ph} . \mathrm{D}$. Candidate.

${ }^{2}$ Associate Professor and Bachman Endowed Chair in Horticultural Marketing.

${ }^{3}$ Professor and Ellison Chair in International Floriculture.

${ }^{4}$ Professor

${ }^{5}$ To whom reprint requests should be addressed e-mail yuechy@umn.edu. occasions (King, 2007). Cut flowers are also important to the U.S. economy. In 2012, the U.S. gross market value (sales volume) of wholesale fresh cut flowers was \$11.7 billion (Society of American Florists, 2013). Bonarriva et al. (2003) concluded that the U.S. cut flower market is attractive to international growers who produce cut flowers at lower costs than U.S. growers. Lower wage rates, less climate control investments, and weaker currencies contribute to lower production costs for international growers compared with domestic producers (Bonarriva et al., 2003). Consequently, in 2012, 64\% of U.S. cut flowers were imported (Society of American Florists, 2013). Ninety-three percent of the 2012 cut flower imports came from Ecuador and Colombia (Society of American Florists, 2013). As a result of the highly perishable nature of cut flowers, the time spent in transit and transportation conditions adversely affect cut flower postharvest vase life (Dole and Wilkins, 1999).

The highly perishable nature of cut flowers amplifies the importance of postharvest vase life management to all supply chain members (producers, wholesalers, retailers, and consumers). Short vase life is a primary purchasing barrier for consumers because a short vase life decreases consumer satisfaction (Ozzambak et al., 2009; Society of American Florists, 2005a) and reduces perceived value. Dissatisfaction discourages consumers from making repeat purchases (Rihn et al., 2011). Yue et al. (2009) concluded greater longevity positively impacts Generation X and Y consumers' purchasing decisions. These studies suggest that floral longevity is a key product characteristic of cut flowers. To date, few studies have investigated consumers' expectations for cut flower longevity or their willingness to pay for cut flowers with longer vase life.

Unlike flower color or form, flower longevity is not readily apparent to consumers when considering a floral purchase. As a result, consumers try to estimate flower longevities while shopping (Jowkar et al., 2007; Smith, 1968). Consumers use their longevity estimates as their internal reference points to determine their post-purchase satisfaction. If the postharvest longevity is less than the internal reference point, the consumer is dissatisfied. Dissatisfaction decreases the consumers' possibility of repurchasing the product (Dennis et al., 2004). Consumers' ability to accurately estimate cut flower vase life varies. Jowkar et al. (2007) found consumers could not accurately estimate how long cut flowers last; however, conflicting conclusions were drawn by Smith (1968) who found consumers are fairly accurate in predicting vase life. Yue et al. (2009) suggested that familiarity with cut flowers increases estimation accuracy for the longevity of cut flowers. These studies lead to the hypothesis that the use of longevity labels might have the potential to mitigate consumers' incorrect estimations by providing consumers with accurate information about the longevities of cut flowers. As a result, consumers' satisfaction may be improved by assisting them in creating more accurate expectations.

Cut flowers in the United States continue to be popular home decor and gift items (Society of American Florists, 2005b). In 2004, 67\% of U.S. cut flowers were purchased as gifts (Society of American Florists, 2005b). Behe et al. (1992) and Huang (2005) determined that having purchased a floral gift in the past positively affected consumers' frequency of any floral purchase. However, studies have found gifts are perceived as riskier than non-gift items because a badly chosen gift harms the relationship between the gift giver and recipient (Roster, 2006). Yue et al. (2009) found that cut flower gifts 
are perceived as riskier than cut flowers purchased for personal enjoyment or as decor items. Therefore, as a result of increased risk with floral gifts, cut flower use may impact the importance of safeguards such as longevity indicators and guarantees.

Guarantees reduce consumers' perceived risk (Dennis et al., 2004). Dennis et al. (2004) demonstrated guarantees decrease consumers' perceived risk for potted plants and also improve consumers' perceptions of floriculture products' quality. Guarantees are a means of minimizing consumers' regret of making a purchase (Dennis et al., 2004; Ortony et al., 1988). Regret often results in switching subsequent purchases to other retailers or products.

Guarantees provide numerous benefits and improve consumer satisfaction. Previous studies showed that product guarantees protect consumers, provide firms a competitive advantage, signal product quality, and provide value to businesses and consumers (Ang and Lee, 2000; Kukar-Kinney and Walters, 2003; Lee and Khan, 2012). Behe and Barton (2000) concluded consumers expect retailers to provide guarantees on rooted plants as a result of anticipating the rooted plants having greater lifespans. In turn, guarantees on rooted plants increase consumer satisfaction (Behe and Barton, 2000).

The benefits of using and communicating guarantees may extend to shorter-lived cut flowers. Rihn et al. (2011) suggested using cut flower guarantees to reduce perceived risks and improve consumers' experiences with floral products. However, Dennis et al. (2003) found a guarantee on Valentine's Day roses did not impact purchasing decisions. Consumers were also unaware of guarantee offerings in floral retail outlets (Dennis et al., 2003). The study conducted by Dennis et al. (2003) was for a specific occasion (Valentine's Day). The impact of guarantees on consumers' cut flower purchases in general (on all occasions) and their willingness to pay (WTP) for cut flower guarantees remains unknown.

In this study, choice experiments were used to determine consumers' preferences for longevity length and presence/absence of a guarantee on cut flower arrangements. The advantages of using choice experiments include flexibility (in terms of experimental design and number of attributes), the ability to gain information on consumer-purchasing behavior, and the capability of identifying the relative importance of product attributes to consumers (Lusk and Shogren, 2007). In the past, choice experiments have been extensively used to determine consumers' preferences and WTP for different horticulture products and product attributes (Chung and Vickers, 2007; James et al., 2009; Koelemeijer and Oppewal, 1999; Yue et al., 2007).

In addition to choice experiments, consumer segmentation has been used to research and target specific subgroups of consumers (Oppenheim, 2000). Specifically, Ward's linkage cluster analysis has been used to identify consumer groups based on consumer behavior and sociodemographic variables (Lessig and Tollefson, 1971; Zarantonello and Schmitt, 2010). Specific marketing efforts can then be developed to target these subgroups. Marketers can more efficiently allocate their marketing dollars to segments on which the marketing strategies might have the greatest impact.

In our study, we focus on current cut flower consumers because retaining existing customers requires less time and financial resources than acquiring new customers (Schiffman and Kanuk, 2007). The overall objective was to explore consumer preferences and WTP for cut flower arrangements with varying vase life longevity and presence/ absence of a guarantee. Specifically, we tested three hypotheses, including: 1) given the same flower type and the same longevity, consumers will prefer cut flowers with a longevity guarantees over cut flowers without a longevity guarantee; 2) given the same flower type, consumers will prefer cut flowers with a longer vase life over cut flowers with a shorter vase life; and 3) consumer preference for cut flower longevity and presence/absence of a guarantee will be heterogeneous; there are different preferences for cut flower longevity and a guarantee.

Our findings could assist florists, floral retailers, floral producers, and other industry stakeholders in determining how much value different consumers place on the use of longevity indicators and/or guarantees. The use of longevity indicators and guarantees could lead to greater sales and potentially higher profits.

\section{Materials and Methods}

Our experiment consisted of three parts: pre-study focus groups, choice experiments, and a survey questionnaire. The study instruments and protocols were reviewed by the Institutional Review Board and were deemed exempt from review under federal guidelines 45 CFR Part 46.101 (b) category \#2 (\#1104E98416).

\section{Pre-study focus groups}

To develop the formal questionnaire, two pre-study focus groups were conducted in St. Paul, MN. For each focus group, 10 participants were recruited from an e-mail list of past study participants from the surrounding communities. Focus group participants were screened to ensure that they had received or purchased cut flowers in the 12 months before the study. Each participant was compensated $\$ 30$ for their time. Participants were asked open-ended questions including: "How would you react to cut flower longevity claims? Would these claims influence your purchasing decision? How would you react to cut flower guarantees? What type of cut flower guarantees would interest you? What are your concerns about cut flower longevity? What are your concerns about cut flower guarantees?" Answers to these questions were then used to develop the formal survey questionnaire.

\section{Experimental set-up}

Choice experiments were conducted to determine the importance of different product attributes and estimate participants' WTP for those attributes. The attributes of longevity, guarantee, price, use, and flower arrangement type resulted in a total of $72(3 * 2 * 3 * 2 * 2)$ possible attribute combinations. To avoid potential participant fatigue, we did not include all of the attribute combinations in the experiment. We used a fractional factorial design to generate 24 choice scenarios. A fractional factorial design is often used to improve experiment efficiency by using only a fraction of the attribute combinations in experiments (Chrzan and Orme, 2000). By using a fractional factorial design, experimenters retain the ability to assess all the attributes in the complete design but reduce the time investment of each participant (Chrzan and Orme, 2000).

Mixed flower arrangements and singlespecies arrangements were selected as the target products for several reasons. First, both types of floral arrangements are commonly offered at retail outlets making the two options representative of a real market choice (Society of American Florists, 2005a). Second, different flower species within a mixed arrangement may have different longevities (whereas an arrangement consisting of the same species of flower would have a similar longevity). The flower composition may impact consumers' value of longevity indicators and/or guarantees (Koelemeijer and Oppewal, 1999). The arrangement longevity may be restricted by the flower lasting the shortest time period. Roses (Rosa $\times$ hybrida) were selected for the single-species arrangement because they are the most popular flower sold at florists (Green, 2011).

For each scenario, participants were shown images of the cut flower arrangements (similar to Koelemeijer and Oppewal, 1999) and were asked to make one of three choices: Arrangement A, Arrangement B, or neither arrangement. Twelve of the scenarios used mixed flower arrangements (containing Antirrhinum majus L., Tulipa sp. L., Gloriosa superb L., Ranunculus asiaticus L., Chamelaucium uncinatum Shauer) and 12 of the scenarios used single-species arrangements [six red roses (Rosa $\times$ hybrida L.) with a filler flower (Gyposphila paniculata L.)]. Each participant was asked to evaluate the alternatives for 24 scenarios. For each type of arrangement (mixed vs. single-species arrangements), participants were instructed that they were purchasing the product for themselves (self) for six of the scenarios and they were purchasing the product as gifts for the remaining six scenarios. Figure 1 shows one example of a mixed arrangement choice experiment scenario.

In the choice experiments, product attributes were presented on a product label below the floral image and included arrangement longevity duration ( 5 to $7 \mathrm{~d}, 8$ to $10 \mathrm{~d}, 11$ to $14 \mathrm{~d}$ ), presence/absence of a guarantee, price, and use (gift/self) (Table 1). The use attribute (gift or self) was indicated in the scenario 
Instructions: From the following pairs of cut flower arrangements please choose which you

would prefer to purchase (you may choose "neither" if you would not purchase either). Please

choose only one option. The cut flower guarantee means that you could get reimbursed if the

flowers did not last as long as stated on the label.

Scenario 1 - Consider a situation where you are provided two cut flower choices and you are purchasing one for YOURSELF. Which arrangement would you purchase?

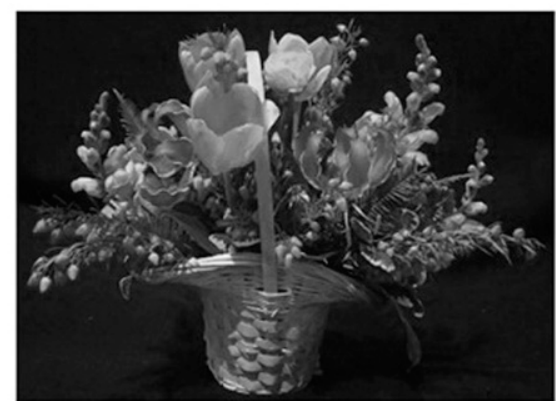

Choice A

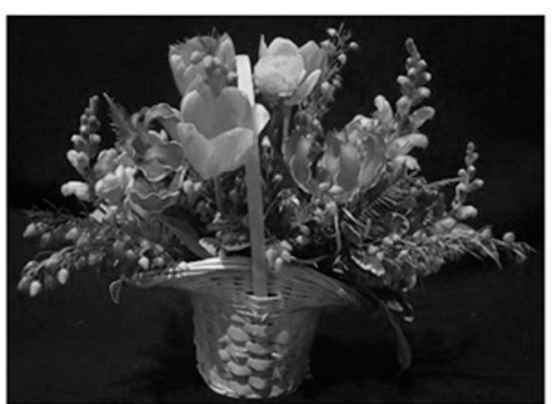

Choice B
Neither

arrangement
Longevity 5-7 days

No Guarantee

Cost $\$ 34.99$
Longevity 8-10 days

Guaranteed

Cost $\$ 37.99$

Fig. 1. An example of one of the 24 online choice experiment scenarios used to investigate consumer preferences for longevity indicators and guarantees on cut flower arrangements in an online U.S. consumer preference study conducted in 2011.

Table 1. Choice experiment attributes and attribute levels (mixed arrangement, single species arrangement) used to develop 24 choice experiment scenarios for an online U.S. cut flower consumer preference study conducted in 2011.

\begin{tabular}{lcc}
\hline & \multicolumn{2}{c}{ Attribute levels } \\
\cline { 2 - 3 } Attributes & Mixed arrangement & Single-species arrangement \\
\hline Longevity $^{z}$ & $5-7 \mathrm{~d}$ & $5-7 \mathrm{~d}$ \\
& $8-10 \mathrm{~d}$ & $8-10 \mathrm{~d}$ \\
Guarantee $^{\mathrm{y}}$ & $11-14 \mathrm{~d}$ & $11-14 \mathrm{~d}$ \\
& Yes & Yes \\
Price & No & No \\
& $\$ 34.99$ & $\$ 7.99$ \\
Use & $\$ 37.99$ & $\$ 9.99$ \\
& $\$ 43.99$ & $\$ 11.99$ \\
& Self & Self \\
\hline
\end{tabular}

"Longevity length was defined as "how long the cut flowers would last."

${ }^{y}$ Guarantee indicated whether the provided longevity was guaranteed.

introduction. The longevity levels were determined from previous studies showing what consumers expected cut flower longevity to be and from suggestions by industry professionals (Fanourakis et al., 2013; Regan et al., 2006, 2007, 2008; Särrkä et al., 2001; Teklic et al., 2003; Yue et al., 2009). Longevity guarantee was either present or absent. Price levels for the arrangements were determined based on prices of comparable products at several floral outlets (e.g., florists, supermarkets, and online sources).
On completion of the choice experiment scenarios, participants were asked to complete the remaining survey questionnaire questions. The survey questionnaire included Likert scale questions addressing participants' attitudes toward cut flower longevities and guarantees and their sociodemographics. The sociodemographic questions included age, education, gender, income, and number of persons in the household.

Participant recruitment and sampling. Qualtrics Online Survey Software (Qualtrics, LLC, Provo, UT) was used to create the online questionnaire. A third-party contractor, MarketTools, was hired to collect the data from a U.S. consumer panel during July 2011. The advantages of using an online survey include rapid deployment, reduced costs, high response rates, and improved access to a broader sample (McDaniel and Gates, 2010). Participants were screened based on U.S. population demographics, geographical location, and on whether they had purchased or received cut flowers in the 12 months before 
the study. All participants were asked the screening question, "Have you purchased or received cut flowers in the past 12 months?" If a participant had purchased or received cut flowers in the previous 12 months, he or she was asked to complete the choice experiments and questionnaire. MarketTools compensated participants with online reward points.

\section{Data analysis}

Econometric model. We used STATA/IC 11 (StataCorp, LP, College Station, TX) to analyze the data. Specifically, we used a mixed logit model to estimate consumers' preferences and WTP for different flower attributes. Mixed logit models capture the correlations between the choices made by the same participants (Train, 2003). Consumer preferences and WTP for different attribute levels are determined by measuring the underlying utility/satisfaction the consumer derived from the selected product. The utility an individual $i$ derived from option $j$ in scenario $s$ is represented by

$$
U_{i j s}=\beta^{\prime} \boldsymbol{x}_{i j s}+\boldsymbol{\eta}_{i}^{\prime} \mathbf{z}_{i j s}+\varepsilon_{i j s}
$$

where $\boldsymbol{x}_{i j s}$ and $\boldsymbol{z}_{i j s}$ are vectors of observed variables for individual $i$. $\boldsymbol{x}_{i j s}$ includes the variables guarantee, longevity, and price, whereas $z_{i j s}$ includes participants' sociodemographic variables as well the random individual effect. $\beta$ is a vector of fixed coefficients. $\eta$ is a vector of random terms with mean zero (the terms in $\eta$ are error components). $\varepsilon_{i j s}$ is an independent and identically distributed (iid) extreme value error term. When a value is iid, each of the variables has the same probability distribution and the variables are not correlated. In the rest of the models, the term $s$ is suppressed (Alfnes et al., 2006).

The density of $\eta$ is denoted by $f(\eta \mid \mathbf{\Omega})$, where $\boldsymbol{\Omega}$ indicates the fixed parameter of the distribution. The conditional choice probability is a standard logit for a given $\eta$

$$
L_{i j}(\boldsymbol{\eta})=\frac{\mathrm{e}^{\beta^{\prime} x_{i j}+\eta_{i}^{\prime} z_{i j}}}{\sum_{n \in N} \mathrm{e}^{\beta^{\prime} x_{i j}+\eta_{i}^{\prime} z_{i j}}}
$$

As a result, the unconditional choice probability, $P$, in the mixed logit model is expressed as follows:

$$
P=\int L_{i j}(\boldsymbol{\eta}) f(\boldsymbol{\eta} \mid \Omega) d \boldsymbol{\eta}
$$

where the logit formula is incorporated into all of the $\eta$ values with the density of $\eta$ as weights.

Specifically, participants' utility is defined as

$$
\begin{aligned}
\hat{U}_{i j}= & \hat{\beta}_{0 j}+\hat{\beta}_{1} \text { Gurantee }_{i j}+\hat{\beta}_{2} \text { Longevity }_{i j} \\
& +\hat{\beta}_{3} \text { Price }_{i j}+\hat{\beta}_{4} \text { Age }_{i j}+\hat{\beta}_{5} \text { Gender }_{i j} \\
& +\hat{\beta}_{6} \text { Income }_{i j}+\hat{\beta}_{7} \text { Household }_{i j} \\
& +\hat{\beta}_{8} \text { Education }_{i j}+\hat{\beta}_{9} \text { In_Relationship }_{i j} \\
& +\delta_{i}+\varepsilon_{i j} ; i=1, \ldots, 525(n)
\end{aligned}
$$

$\hat{U}_{i j}$ is the latent unobservable utility that participant $i$ obtains from choosing alternative $j$ and it is measured by the observed choice. Specifically, $\hat{U}_{i j}$ is the utility/satisfaction that consumer $i$ derives from alternative $j$; Guarante $_{i j}$ is a dummy variable equal to one if the arrangement is guaranteed and zero otherwise; Longevity $_{i j}$ is the longevity (in days) of alternative $j$; Price $_{i j}$ is the price of alternative $j ; A g e_{i j}$ is the age of participant $i$; Gender $_{i j}$ is a dummy variable equal to one if the participant is male and zero otherwise; Income $_{i j}$ is the 2010 household income of participant $i$; Household $_{i j}$ is the household size of participant $i$; Education $_{i j}$ is the level of education completed by participant $i$; In_Relationship ${ }_{i j}$ is a dummy variable equal to one if the participant is in a relationship and zero otherwise. $\delta_{i}$ is the random individual effect that captures the correlation between the choices made by the same participants; $\varepsilon_{i j}$ is the residual error term that is not captured by the explanatory variables, which is assumed to follow a normal distribution with mean zero and SD $\sigma_{\varepsilon}$. There were $525(i)$ participants and six $(j)$ alternatives in each model. We estimated four mixed logit models based on use (gift or self) and arrangement type (multiple species of flowers or single species of cut flowers). To avoid multicollinearity, no guarantee and 5-7 d longevity were used as the base variables in the estimation.

WTP for an attribute level is defined as the premium participants are willing to pay for an attribute level in comparison with the base level of the attribute (Lusk and Shogren, 2007). The WTP estimate for an attribute is determined by dividing the coefficient of an attribute $\left(\hat{\beta}_{j}\right)$ by the coefficient of price $\left(\hat{\beta}_{3}\right)$ and multiplying by -1 ,

$$
\mathrm{WTP}_{\mathrm{ij}}=-1 \times\left(\frac{\frac{\partial \mathrm{U}}{\partial \mathrm{A}_{\mathrm{j}}}}{\frac{\partial \mathrm{U}}{\partial \text { Price }}}\right)=-1 \times \frac{\hat{\beta}_{j}}{\hat{\beta}_{3}}
$$

WTP $_{\mathrm{ij}}$ denotes participant $i$ 's WTP for product attribute $j$.

Factor and cluster analysis. To identify potential consumer groups or clusters, we first performed a factor analysis on the attitudinal questions using STATA/IC 11 software (StataCorp, LP, College Station, TX). Factor analysis is a method used to extract latent constructs, identified as factors, from a larger number of variables (Loehlin, 1998). We subjected the 24 attitudinal questions to a principal component factor analysis. A Cronbach's alpha is a measure of internal consistency among the attitudinal questions; a value greater than 0.70 is considered an acceptable level of internal consistency (Tavakol and Dennick, 2011). We also used the principal component factor analysis to determine the amount of variance accounted for by the factors identified.

After the factor analysis, we subjected the data to a Ward's linkage cluster analysis to segment participants based on their stated preferences. A Ward's linkage cluster analysis minimizes the variance within the clusters (Ward, 1963; Zarantonello and Schmitt, 2010). We used cluster analysis to segment consumers into different groups with similar preferences. Subsequently, we conducted pairwise $t$ tests to examine whether the factors differed between the clusters.

\section{Results}

A total of 525 people participated in the choice experiments and online survey. The mean age of participants was 43 years old (Table 2). Most participants had received their college diploma. Fifty-five percent of participants were female. We anticipated having an older sample with a higher percentage of women because older (age older than 55 years) females are the core consumers for cut flowers (Society of American Florists, 2005b). Seventy-two percent of participants were married or in a relationship. The mean number of persons in the household was two to three. The mean 2010 household income was $\$ 63,062$ (the U.S. Census Bureau statistics from 2010 are provided in Table 2 for comparison purposes). Although we cannot make statistical comparisons between the mean values as a result of a lack of standard deviation of the census data, overall, our sample was slightly older, had completed a higher level of education, and had a higher 2010 household income level than the U.S. population. These differences are likely the result of screening potential participants to include only current cut flower consumers.

Estimation results of the mixed logit models. The presence of a guarantee increased the probability that participants selected the cut flower arrangement for both mixed and single-flower species arrangements (Table 3). Therefore, the first hypothesis, "Given the same flower type and the same longevity, cut flowers with longevity guarantees are preferred to cut flowers without longevity guarantees by consumers," was supported. The negative sign and the significance of the coefficient for price indicate that as price increases, the probability of choosing the cut flower arrangement significantly decreases. Compared with the base of 5- to 7-d cut flower longevity, participants preferred cut flowers with the 11- to 14-d longevity the most followed by the 8 - to 10 -d longevity. Therefore, the second hypothesis, "Given the same flower type, cut flowers with longer vase life are preferred to cut flowers with shorter vase life by consumers," was supported.

Regarding floral arrangements purchased as gifts, the presence of a guarantee increased the probability of selecting both types of arrangements (Table 3). Additionally, participants preferred floral gifts with a greater longevity. Compared with the 5- to 7-d longevity, participants were most interested in and valued cut flowers with the 11- to 14-d longevity indicators followed by 8 - to $10-\mathrm{d}$ longevity in both types of arrangements. The first two hypotheses were supported for cut flowers used as gifts.

Consumer willingness-to-pay estimates. Participants were willing to pay the highest premium for an arrangement with the most longevity (Table 4). Specifically, if the mixed 
Table 2. Summary statistics (variable, description of variable, mean $\pm \mathrm{sE}$, the 2010 U.S. Census mean) for sociodemographic variables of participants in a U.S. online cut flower consumer preference study conducted in $2011(\mathrm{n}=525)$.

\begin{tabular}{|c|c|c|c|}
\hline Variable & Description of variables & Mean \pm SE & 2010 U.S. Census mean \\
\hline Education & $\begin{array}{l}\text { Highest level of education completed } \\
1=\text { some high school/less } \\
2=\text { high school diploma } \\
3=\text { some college } \\
4=\text { college diploma } \\
5=\text { some graduate school } \\
6=\text { graduate degree }\end{array}$ & $4.28 \pm 1.49$ & High school graduate \\
\hline Gender & $\begin{array}{l}\text { Gender of participant } \\
1=\text { male } \\
0=\text { female }\end{array}$ & $0.45 \pm 0.50$ & 49.2 \\
\hline Relationship & $\begin{array}{l}\text { Relationship status of participant } \\
1=\text { married/in a relationship } \\
0=\text { not married/not in a relationship }\end{array}$ & $0.72 \pm 0.45$ & NA \\
\hline Household & $\begin{array}{l}\text { Number of people in household, including dependents and spouse, } \\
\text { excluding roommates/renters }\end{array}$ & $2.82 \pm 1.48$ & 2.54 \\
\hline Income & 2010 gross income of participants ( $\$ 1000$ USD) & $63.06 \pm 32.00$ & 51.10 \\
\hline
\end{tabular}

${ }^{\mathrm{z} U . S . ~ C e n s u s ~ B u r e a u, ~} 2013$.

$\mathrm{NA}=$ not available.

Table 3. Mixed logit model coefficient estimates (mean $\pm \mathrm{SE}$ ) for U.S. cut flower consumers' preferences for longevity information and guarantees on cut flower arrangements for self- and gift use from an online U.S. consumer preference study conducted in $2011(\mathrm{n}=525)$. $^{\mathrm{z}}$

\begin{tabular}{|c|c|c|c|c|}
\hline \multirow[b]{2}{*}{ Variables } & \multicolumn{2}{|c|}{ Mixed flower arrangement } & \multicolumn{2}{|c|}{ Single-species arrangement } \\
\hline & Self $^{y}$ & Gift $^{y}$ & Self $^{y}$ & Gift $^{y}$ \\
\hline No guarantee & Base & Base & Base & Base \\
\hline $8-10 \mathrm{~d}$ longevity & $1.109 \pm 0.070^{* * *}$ & $1.096 \pm 0.070^{* * *}$ & $1.267 \pm 0.069^{* * *}$ & $1.127 \pm 0.069^{* * *}$ \\
\hline 11-14 d longevity & $1.812 \pm 0.105^{* * *}$ & $1.779 \pm 0.103^{* * *}$ & $2.016 \pm 0.097 * * *$ & $1.823 \pm 0.096^{* * *}$ \\
\hline Gender & $-0.043 \pm 0.086$ & $-0.011 \pm 0.083$ & $0.021 \pm 0.047$ & $-0.013 \pm 0.047$ \\
\hline Education & $-0.088 \pm 0.090$ & $-0.097 \pm 0.087$ & $-0.063 \pm 0.049$ & $-0.060 \pm 0.049$ \\
\hline Household & $-0.098 \pm 0.090$ & $-0.165 \pm 0.087^{*}$ & $0.022 \pm 0.049$ & $0.030 \pm 0.049$ \\
\hline Income & $0.028 \pm 0.091$ & $0.078 \pm 0.088$ & $-0.030 \pm 0.050$ & $0.014 \pm 0.051$ \\
\hline In relationship & $-0.053 \pm 0.098$ & $0.069 \pm 0.095$ & $0.063 \pm 0.054$ & $0.084 \pm 0.054$ \\
\hline Intercept & $9.979 \pm 0.483^{* * *}$ & $9.835 \pm 0.476^{* * *}$ & $4.195 \pm 0.235^{* * *}$ & $3.649 \pm 0.233 * * *$ \\
\hline Random individual effect & $0.864 \pm 0.048$ & $0.830 \pm 0.047$ & $5.03 \mathrm{e}-11 \pm 0.035$ & $5.64 \mathrm{e}-11 \pm 0.040$ \\
\hline
\end{tabular}

${ }^{2}$ A higher coefficient indicates a higher probability of selection when compared with the base variable.

y***, **, * Significant at $P \leq 0.01,0.05$, or 0.10 , respectively, when compared with the $5-7 d$ longevity or no guarantee variables.

Table 4. Participants' willingness-to-pay estimates for different product attribute levels for mixed flower arrangements and single-species arrangements, by use (self-/gift), based on a mixed logit model analysis of U.S. online choice experiment of cut flower consumer preferences conducted in 2011 $(\mathrm{n}=525)$.

\begin{tabular}{|c|c|c|c|c|}
\hline \multirow[b]{2}{*}{ Attribute } & \multicolumn{2}{|c|}{ Mixed flower arrangement } & \multicolumn{2}{|c|}{ Single species arrangement } \\
\hline & Self $^{z}$ & $\mathrm{Gift}^{\mathrm{z}}$ & Self $^{z}$ & $\mathrm{Gift}^{\mathrm{z}}$ \\
\hline Guarantee & $2.762 * * *$ & $3.315 * * *$ & $1.910 * * *$ & $2.056 * * *$ \\
\hline No guarantee & Base & Base & Base & Base \\
\hline 5-7 d longevity & Base & Base & Base & Base \\
\hline 8-10 d longevity & $3.590 * * *$ & $3.557 * * *$ & $2.041 * * *$ & $2.017 * * *$ \\
\hline 11-14 d longevity & $5.862 * * *$ & $5.773 * * *$ & $3.249 * * *$ & $3.262 * * *$ \\
\hline Base price & $32.297 * * *$ & $31.909 * * *$ & $6.760 * * *$ & $6.529 * * *$ \\
\hline
\end{tabular}

z***,**, * Significant at $P \leq 0.01,0.05$, or 0.10 , respectively, when compared with the $5-7 d$ longevity or no guarantee variables.

arrangement would last 11 to $14 \mathrm{~d}$, participants were willing to pay the highest premiums (\$5.86 more for an arrangement purchased for self-use and $\$ 5.77$ for an arrangement purchased to be given as a gift). Participants were willing to pay slightly less ( $\$ 3.59$ for self-use and $\$ 3.58$ for gift use) for mixed flower arrangements lasting 8 to $10 \mathrm{~d}$. For single-species arrangements, participants were willing to pay the highest premiums for arrangements with an 11- to 14-d longevity ( $\$ 3.25$ for self-use and \$3.26 for gift use). Similar to the mixed arrangement results, participants were willing to play slightly less for singlespecies arrangements with an 8- to 10-d longevity (\$2.04 for self-use and \$2.02 for gift use).
Participants were also willing to pay a premium for a guaranteed arrangement compared with an arrangement without a guarantee (Table 4). If participants were purchasing a mixed species arrangement as a gift, they were willing to pay $\$ 3.32$ more for a guaranteed arrangement. They were willing to pay $\$ 2.76$ more for a guarantee on a mixed arrangement they purchased for self-use. Similarly, participants were willing to pay $\$ 2.06$ more for a guarantee on a single-species arrangement purchased as a gift and $\$ 1.91$ more for a guarantee on a single-species arrangement purchased for self-use.

Overall, participants valued guarantees and extended longevity on cut flower arrangements, supporting our hypotheses. However, contrary to the WTP estimates, when we compared the WTP premium percentages [(WTP premium/base price $) \times 100 \%$, the single-species arrangements had the higher WTP premium percentage for floral guarantee and longevity when compared with 
the mixed arrangements. Pre-study focus group participants expressed skepticism about ing of more than one species of cut flowers. Therefore, the higher WTP premium percentage on single-species arrangements is likely the result of increased confidence in the retailers' ability to accurately predict longevity.

Factor and cluster analysis. Two factors (e.g., long_label_support and long_label_ mistrust) emerged that described participants' attitudes toward cut flower longevity indicators (Table 5). Three factors emerged (e.g., guar_supporter, guar_over_flwtype, and security) to describe participants' attitudes toward cut flower guarantees (Table 6). Two factors emerged (e.g., giver_longlabel and recipient_longlabel) to describe participants' attitudes toward cut flower guarantees when the flowers are used as gifts (Table 7). We calculated individual factor scores, which we used in the subsequent analyses.

Using the individual factor scores, we performed a Ward's linkage cluster analysis to segment participants based on their stated preferences. Three distinct consumer clusters were identified, hereafter referred to as guarantee seekers, value-conscious consumers, and spenders. Thus, our third hypothesis, longevity accuracy on arrangements consist-

"There exists different segments in terms of consumer preferences for cut flower longevities and longevity guarantees," was supported. Forty-nine percent of participants were guarantee seekers, $31 \%$ were value-conscious consumers, and $20 \%$ were members of the spenders cluster. A summary of the clusters' mean values for all factors and sociodemographic variables is presented in Table 8 .

Guarantee seekers were on average 43.6 years old (Table 8). The majority were in a relationship and the majority $(60 \%)$ were females. The average 2010 household income for guarantee seekers was $\$ 63,326$. The guarantee seekers were more likely to select cut flowers with a specified guarantee (as indicated in the higher mean factor score for the guar_over_flwtype variable; Table 8). As gift givers, guarantee seekers preferred guaranteed flowers and longevity labels. However, as gift recipients, they did not want longevity information about the flowers.

The value-conscious consumers had the lowest mean income compared with the other two clusters (Table 8). Additionally, the valueconscious consumers had completed a lower level of education than the other clusters. Value-conscious consumers were older, in a relationship, and had a higher percentage of

Table 5. Factor analysis (Factor 1, long_label_support; Factor 2, Long_label_mistrust) factor loadings of questionnaire statements regarding participants' opinions and attitudes about cut flower longevity information. ${ }^{\mathrm{z}}$

\begin{tabular}{lcc}
\hline Questionnaire statements $^{\mathrm{yxw}}$ & $\begin{array}{c}\text { Factor1 } \\
\text { Long_label_support }\end{array}$ & $\begin{array}{c}\text { Factor2 } \\
\text { Long_label_mistrust }\end{array}$ \\
$\begin{array}{l}\text { I like the idea of knowing how long } \\
\text { to expect cut flowers to last. }\end{array}$ & 0.6609 & 0.2463 \\
$\begin{array}{l}\text { I would be more likely to purchase } \\
\quad \text { flowers with longevity information. }\end{array}$ & 0.6697 & 0.2289 \\
$\begin{array}{l}\text { I would trust longevity information } \\
\quad \text { at a flower shop. }\end{array}$ & 0.7441 & -0.1860 \\
$\begin{array}{l}\text { I would trust a longevity information } \\
\text { from a supermarket/grocery }\end{array}$ & 0.6266 & -0.2835 \\
\hline
\end{tabular}

${ }^{\mathrm{z}} \mathrm{A}$ higher value indicates a higher level of agreement.

y The questionnaire statements were developed from pre-study focus groups.

${ }^{\mathrm{x}} \mathrm{A}$ Likert scale was used to measure participants' level of agreement with the variable statements where $1=$ strongly disagree and $7=$ strongly agree.

${ }^{\text {w}}$ Variance $=91 \%$ and Cronbach's alpha $=0.7800$ females than the other two clusters. Overall, the value-conscious consumers preferred longevity information and a guarantee on cut flowers more (as evidenced by the higher mean factor scores for long_label_support and guar_support factors; Table 8). Valueconscious consumers also trusted longevity indicators the most among the three clusters (as indicated by the highest mean factor score for the long_label_mistrust factor; Table 8). Value-conscious consumers actively sought the best value-added attributes for their money.

On average, spenders were the youngest cluster (Table 8). Spenders had the highest percentage of males and the highest mean income among the three clusters. Spenders also had completed a higher level of education and had a lower percentage of participants in a relationship when compared with the other two clusters. Overall, spenders were not interested in longevity information or guarantees on cut flower arrangements regardless of arrangement type or use (as captured in the long_label_support and guar_supporter factors; Table 8). However, spenders were more interested in guarantees on more expensive arrangements (indicated by the security factor). Furthermore, spenders were marginally supportive of longevity indicators when they were the floral gift recipients (indicated by the higher recipient_longlabel factor mean score).

Cluster willingness-to-pay estimates. The WTP estimates varied between clusters (Table 9). Regardless of use, guarantee seekers were willing to pay the highest premium of $\$ 5.32$ for self-use and $\$ 5.62$ for gift use for the 11- to 14-d longevity on the mixed flower arrangement followed by the 8- to 10 -d longevity at $\$ 3.23$ for self-use and $\$ 3.47$ for gift use when compared with mixed arrangements lasting 5 to $7 \mathrm{~d}$. The guarantee seekers were also willing to pay a premium for a longevity guarantee regardless of use ( $\$ 2.22$ for self-use and $\$ 3.03$ for gift use) when compared with an arrangement without a guarantee. Similarly, for the single-species arrangement, guarantee

Table 6. Factor analysis (Factor 3, Guar_supporter; Factor 4, Guar_over_flwtype; Factor 5, Security) factor loadings of questionnaire statements regarding participants' opinions and attitudes about cut flower guarantees. ${ }^{\mathrm{z}}$

\begin{tabular}{|c|c|c|c|}
\hline Questionnaire statements ${ }^{\mathrm{yxw}}$ & $\begin{array}{c}\text { Factor } 3 \\
\text { Guar_supporter }\end{array}$ & $\begin{array}{c}\text { Factor } 4 \\
\text { Guar_over_flwtype }\end{array}$ & $\begin{array}{l}\text { Factor } 5 \\
\text { Security }\end{array}$ \\
\hline I would be excited about cut flower longevity guarantees. & 0.1333 & -0.1396 & -0.1271 \\
\hline I would want to buy flowers more often because of guarantees. & 0.1298 & -0.4462 & -0.1309 \\
\hline A guarantee would improve my confidence in the flowers lasting longer. & 0.1492 & 0.1171 & -0.0955 \\
\hline $\begin{array}{l}\text { If offered a guarantee, I would choose the guaranteed cut flowers over non-guaranteed cut flowers } \\
\text { of equal price. }\end{array}$ & 0.0928 & 0.2832 & -0.1477 \\
\hline When considering the same type of flower, I would choose the guaranteed ones. & 0.1234 & 0.2122 & -0.2628 \\
\hline I would be more comfortable spending more money on an expensive floral product with a guarantee. & 0.1172 & 0.2566 & 0.3561 \\
\hline If I saw cut flower guarantees often in promotions I would purchase more flowers. & 0.1473 & -0.3821 & 0.3477 \\
\hline $\begin{array}{l}\text { I would likely bring my flowers back for a full refund if they did not last as long as the minimum number } \\
\text { of days. }\end{array}$ & 0.0519 & 0.0384 & 0.0595 \\
\hline The more expensive the bouquet is, the more willing I am to pay for a guarantee. & 0.0645 & 0.1217 & 0.30 \\
\hline
\end{tabular}

${ }^{\mathrm{z}} \mathrm{A}$ higher value indicates a higher level of agreement.

${ }^{y}$ The questionnaire statements were developed from pre-study focus groups.

${ }^{\mathrm{x}} \mathrm{A}$ Likert scale was used to measure participants' level of agreement with the variable statements where $1=$ strongly disagree and $7=$ strongly agree.

${ }^{\mathrm{w}}$ Variance $=90 \%$ and Cronbach's alpha $=0.9185$. 
Table 7. Factor analysis (Factor 6, Giver_longlabel; Factor 7, Recipient_longlabel) factor loadings of questionnaire statements regarding participants' opinions and attitudes about cut flower longevity information on floral gifts. ${ }^{z}$

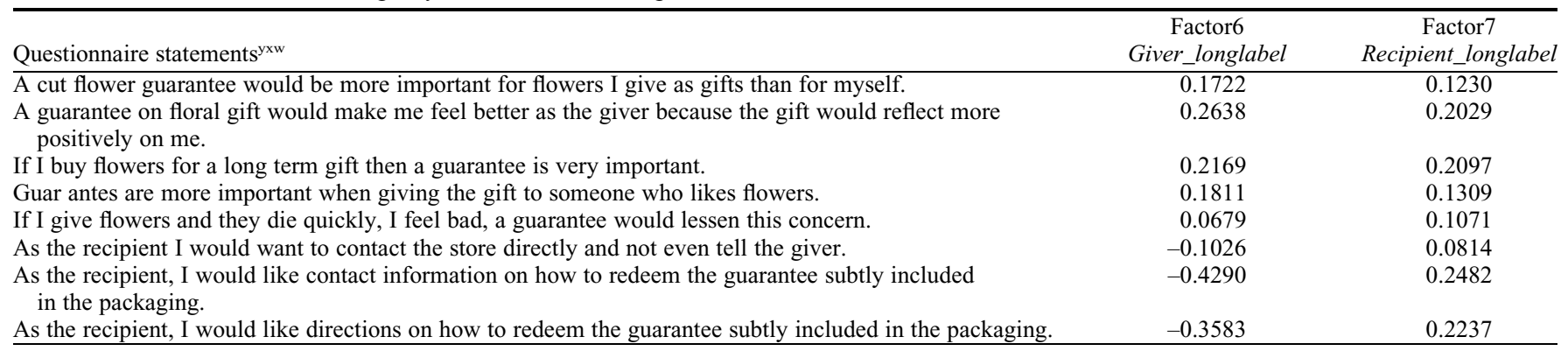

${ }^{\mathrm{z}} \mathrm{A}$ higher value indicates a higher level of agreement.

${ }^{\mathrm{y}}$ The questionnaire statements were developed from pre-study focus groups.

${ }^{\mathrm{x}} \mathrm{A}$ Likert scale was used to measure participants' level of agreement with the variable statements where $1=$ strongly disagree and $7=$ strongly agree.

${ }^{\mathrm{w}}$ Variance $=91 \%$ and Cronbach's alpha $=0.8480$.

Table 8. Factor means of three cut flower consumer clusters derived from Ward's linkage cluster analysis based on an online U.S. cut flower consumer preference study conducted in 2011 regarding their attitudes and opinions about cut flower longevity indicators and guarantees $(\mathrm{n}=525)$.

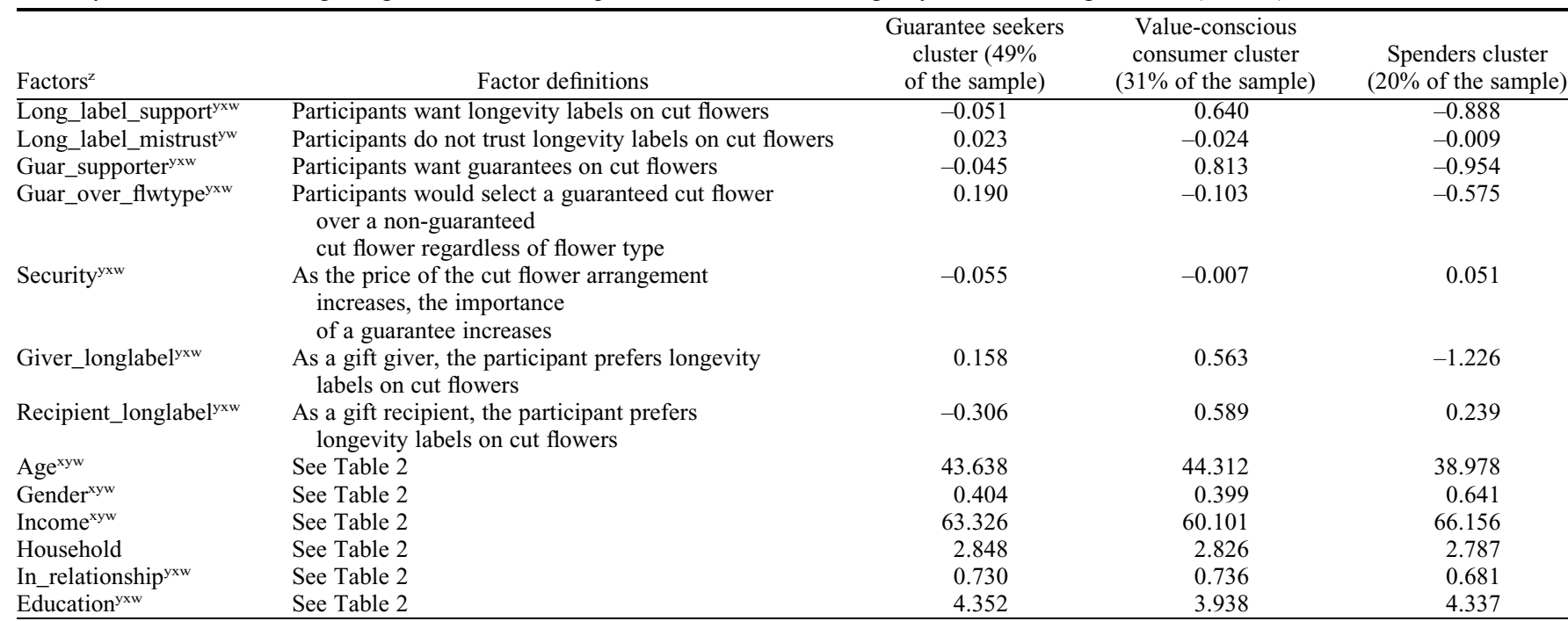

${ }^{2}$ Pairwise $t$ tests were performed to determine significance between clusters.

${ }^{\text {y }}$ Significant difference between guarantee seekers cluster and value-conscious consumer cluster $(P \leq 0.010)$.

${ }^{\mathrm{x}}$ Significant difference between guarantee seekers cluster and the spenders cluster $(P \leq 0.010)$.

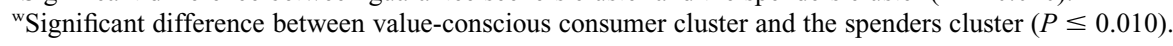

seekers had the highest WTP for the 11- to 14-d longevity with $\$ 2.93$ for self-use and $\$ 3.13$ for gift use followed by the 8- to 10 -d longevity at $\$ 3.13$ for self-use and $\$ 2.03$ for gift use. The coefficients for 11- to 14-d longevity and 8- to 10-d longevity were significant and positive, which indicated that participants were willing to pay more for longer longevity. Guarantee seekers were also willing to pay a premium for a guarantee on the single-species arrangement ( $\$ 1.73$ for self-use and \$1.66 for gift use) when compared with a similar arrangement without a guarantee.

Regardless of the use of cut flowers, the value-conscious consumers were willing to pay the most ( $\$ 7.55$ for self-use, $\$ 7.58$ for gift use) for the 11- to 14-d longevity on the mixed arrangement followed by the 8- to 10-d longevity ( $\$ 4.65$ for self-use, $\$ 4.43$ for gift use) when compared with the 5- to 7-d longevity (Table 9). Value-conscious consumers were also willing to pay substantially more ( $\$ 5.04$ for self-use, $\$ 5.99$ for gift use) to obtain a guarantee on the mixed arrangement. Similarly, for the single-species arrangement, the value-conscious consumers were willing to pay the highest premium for the 11- to 14-d longevity ( $\$ 5.60$ for self-use, $\$ 4.85$ for gift use) followed by the 8- to 10-d longevity (\$4.40 for self-use, $\$ 4.54$ for gift use) when compared with the 5- to 7-d longevity. Valueconscious consumers were also willing to pay a premium for guarantees on the single-species arrangement regardless of the use of cut flowers ( $\$ 3.13$ for self-use, $\$ 4.59$ for gift use).

For arrangements for self-use or as a gift, the spenders were willing to pay the greatest premium for the 11- to 14-d longevity on the mixed arrangements ( $\$ 4.30$ for self-use, $\$ 3.37$ for gift use) followed by the 8- to $10-\mathrm{d}$ longevity ( $\$ 2.80$ for self-use, $\$ 2.15$ for gift use) when compared with the 5- to 7-d longevity (Table 9). Spenders were willing to pay $\$ 1.19$ more for a guarantee on a mixed arrangement for themselves to enjoy when compared with a non-guaranteed arrangement. However, the spenders were not willing to pay a premium for a guarantee on a mixed arrangement purchased as a gift. For the single-species arrangement, the spenders were willing to pay a premium for the 11- to 14-d longevity (\$2.64 for self-use, \$2.55 for gift use) and for the 8- to 10-d longevity ( $\$ 1.49$ for self-use, $\$ 1.61$ for gift use) when compared with 5- to $7-d$ longevity. Spenders were also willing to pay substantially more for a guarantee on the single-species arrangements $(\$ 0.80$ for selfuse, $\$ 0.72$ for gift use) compared with similar arrangements without guarantees.

Interestingly, WTP for longevity and guarantee premiums did not constitute the entirety of the findings. When the premiums were added to the base prices, we obtained the total WTP. We found spenders had the highest total WTP followed by the guarantee seekers and the value-conscious consumers (Table 9). Although the spenders were the least interested in longevity indicators and guarantees, they were willing to pay the most for cut flower arrangements whether they had those attributes. Conversely, the value-conscious consumers 
Table 9. Cluster members' willingness-to-pay estimates for different product attribute levels compared with the base price for cut flower arrangements purchased for self- and gift use based on an online choice experiment of U.S. cut flower consumer preferences conducted in $2011(\mathrm{n}=525)$.

\begin{tabular}{|c|c|c|c|c|c|c|}
\hline \multirow[b]{3}{*}{ Variables } & \multicolumn{6}{|c|}{ Mixed-species arrangement } \\
\hline & \multicolumn{2}{|c|}{ Guarantee Seekers } & \multicolumn{2}{|c|}{ Value-conscious consumer } & \multicolumn{2}{|c|}{ Spenders } \\
\hline & Self Premium $^{z}$ & Gift Premium $^{z}$ & Self Premium $^{z}$ & Gift Premium $^{z}$ & Self Premium $^{z}$ & Gift Premium $^{z}$ \\
\hline Guarantee & $2.220 \pm 0.210^{* * *}$ & $3.028 \pm 0.221 * * *$ & $5.042 \pm 0.417 * * *$ & $5.993 \pm 0.401 * * *$ & $1.193 \pm 0.430 * * *$ & $0.002 \pm 0.476$ \\
\hline No guarantee & Base & Base & Base & Base & Base & Base \\
\hline $5-7 \mathrm{~d}$ longevity & Base & Base & Base & Base & Base & Base \\
\hline 8-10 d longevity & $3.233 \pm 0.250^{* * *}$ & $3.566 \pm 0.271 * * *$ & $4.650 \pm 0.490 * * *$ & $4.432 \pm 0.426^{* * *}$ & $2.803 \pm 0.469 * * *$ & $2.147 \pm 0.459^{* * *}$ \\
\hline 11-14 d longevity & $5.315 \pm 0.260 * * *$ & $5.623 \pm 0.274 * * *$ & $7.550 \pm 0.474 * * *$ & $7.576 \pm 0.418 * * *$ & $4.296 \pm 0.533 * * *$ & $3.374 \pm 0.571 * * *$ \\
\hline Base price & $33.107 \pm 0.729 * * *$ & $31.637 \pm 0.762 * * *$ & $29.519 \pm 1.289 * * *$ & $29.904 \pm 1.119 * * *$ & $34.454 \pm 1.706^{* * *}$ & $35.553 \pm 1.910 * * *$ \\
\hline Number of observations & 4052 & 4074 & 2296 & 2302 & 1364 & 1372 \\
\hline \multirow[t]{3}{*}{ Log likelihood } & -2387.180 & -2465.009 & -1449.639 & -1416.754 & -752.872 & -721.099 \\
\hline & \multicolumn{6}{|c|}{ Single-species arrangement } \\
\hline & \multicolumn{2}{|c|}{ Guarantee seekers } & \multicolumn{2}{|c|}{ Value-conscious consumers } & \multicolumn{2}{|c|}{ Spenders } \\
\hline Variables & Self Premium $^{z}$ & Gift Premium $^{z}$ & Self Premium $^{z}$ & Gift Premium $^{z}$ & Self Premium $^{z}$ & Gift Premium $^{z}$ \\
\hline Guarantee & $1.731 \pm 0.095^{* * *}$ & $1.659 \pm 0.110^{* * *}$ & $3.126 \pm 0.238 * * *$ & $4.592 \pm 0.432 * * *$ & $0.805 \pm 0.197 * * *$ & $0.717 \pm 0.180^{* * *}$ \\
\hline No guarantee & Base & Base & Base & Base & Base & Base \\
\hline 5-7 d longevity & Base & Base & Base & Base & Base & Base \\
\hline $8-10$ d longevity & $1.960 \pm 0.116^{* * *}$ & $2.030 \pm 0.137 * * *$ & $2.563 \pm 0.225 * * *$ & $2.723 \pm 0.300 * * *$ & $1.492 \pm 0.233 * * *$ & $1.614 \pm \pm 0.209 * * *$ \\
\hline $11-14 \mathrm{~d}$ longevity & $2.928 \pm 0.112^{* * *}$ & $3.130 \pm 0.132 * * *$ & $4.398 \pm 0.245^{* * *}$ & $4.542 \pm 0.328 * * *$ & $2.639 \pm 0.234 * * *$ & $2.545 \pm 0.213^{* * *}$ \\
\hline Base price & $7.106 \pm 0.215^{* * *}$ & $6.868 \pm 0.255^{* * *}$ & $5.598 \pm 0.454 * * *$ & $4.854 \pm 0.633^{* * *}$ & $7.485 \pm 0.433 * * *$ & $7.219 \pm 0.483^{* * *}$ \\
\hline Number of observations & 4066 & 4066 & 2302 & 2286 & 1376 & 1372 \\
\hline Log likelihood & -2611.129 & -2661.648 & -1439.935 & -1409.381 & -895.182 & -864.802 \\
\hline
\end{tabular}

z***, **, * Significant at $P \leq 0.01,0.05$, or 0.10 , respectively, when compared with the $5-7 d$ longevity or no guarantee variables.

had a much lower base price resulting in the lowest total WTP for longevity or a guarantee of all the clusters.

\section{Discussion and Conclusions}

Longevity indicators and guarantees. Our results showed that participants were interested and willing to pay for a guarantee for both self- and gift use on both types of arrangements, supporting our first hypothesis. Previous studies showed that guarantees reduced consumers' perceived risk when purchasing floral gifts, which resulted in increased consumer satisfaction (Behe and Barton, 2000; Dennis et al., 2004). Our findings are consistent with theirs and show that consumers are interested in cut flower guarantees. Contrary to Dennis et al. (2003) who found that guarantees do not affect consumerpurchasing decisions on cut flowers, our results showed that guarantees affected cut flower consumers' purchasing decisions in a positive way. Our results were consistent with research findings that showed evidence that guarantees are used as quality indicators (Ang and Lee, 2000; Dennis et al., 2004). We concluded that as a value-added tool, longevity guarantees increase consumer interest in and satisfaction with cut flowers.

Our findings also showed that participants were interested in cut flower arrangements with greater longevities for both personal enjoyment and as a gift for both singlespecies and mixed-species arrangement types, supporting our second hypothesis. Our longevity results are slightly intuitive because vase life longevity is directly related to flower quality for consumers (Ozzambak et al., 2009; Society of American Florists, 2005a). In the retail setting, consumers would not be able to see the cut flower longevities; thus, labeling the longevity makes it a creditable attribute. Without a label, consumers may be dissatisfied if their cut flowers do not live as long as expected, similar to what Dennis et al. (2004) found with perennial plants. We concluded that longevity indicators are one means for floral retailers to decrease potential consumer dissatisfaction by supplying reasonable expectations for cut flower longevities.

Consumer segments. Value-conscious consumers were the most interested in longevity information and a guarantee followed by the guarantee seekers and then the spenders. The spenders' lower interest in longevity information and guarantees may be attributed to their demographic characteristics. Cut flowers are typically purchased by older women (Society of American Florists, 2005b), whereas spenders were predominantly younger men. Consequently, spenders may not be as interested in these attributes as the other clusters. Another potential explanation is spenders were more interested in other cut flower arrangement attributes not included here (such as color, fragrance, arrangement style, etc.). Other types or combinations of cut flowers in arrangements are outside the scope of the current study.

Although value-conscious consumers were willing to pay the highest premiums for longevity indicators and guarantees, the base prices indicated spenders had the highest total WTP for floral arrangements. The differences in base prices between the spenders and valueconscious consumers clusters may be partially attributed to different income levels. Specifically, the base prices reflect that spenders had the highest 2010 income and were the least price-sensitive, whereas the value-conscious consumers had the lowest 2010 income and were the most price-sensitive. These results are consistent with Nagle et al. (2011) who demonstrated a strong correlation between income and price sensitivity.

Based on the cluster analysis results, floral retailers can implement target marketing strategies to attract these specific consumer segments. Specifically, to attract the spenders, floral retailers could offer guarantees on their cut flower arrangements. For the guarantee seekers, floral retailers could emphasize and promote guarantees. Regarding the valueconscious consumers, floral retailers can use in-store point-of-purchase materials to promote cut flower longevity and guarantees. Furthermore, retailers could use advertising and other communication campaigns to promote the presence of these attributes to attract value-conscious consumers. Sales promotions could also be used to attract value-conscious consumers as a result of their price sensitivity.

All three clusters had the highest premiums for the greatest longevity regardless of use or arrangement type, supporting our third hypothesis. Future research might help the distribution chain estimate the cost to improve longevity and the cost of labeling to determine if using longevity labels is profitable. They may also explore if the premium of offering guarantees is high enough to cover the corresponding costs (labeling cost, guarantee redemption cost, associated labor cost, etc.). The cluster WTP estimates can be used by retailers to develop target marketing strategies. Specifically, the results can be used to assist in determining the optimal pricing strategies to attract the consumer segment of interest.

Feasibility of longevity indicators and guarantees on cut flowers in the retail setting. Although the present research concluded that providing longevity information and guarantees on cut flowers would benefit floral retailers and consumers alike, predicting postharvest vase life longevity can be challenging. 
During production, factors impacting cut flower longevity include cultivar, species, temperature, post-harvest treatment, susceptibility to diseases, lighting, ethylene sensitivity and presence, transpiration rates, relative humidity, water access and quality, use of flower preservatives, regional differences, parent plant age and care, plant nutrition, damage (as a result of mechanical injury, insects, or disease), developmental stage, harvest time, and other environmental conditions (de Gelder, 1989; Dole and Wilkins, 1999; Fanourakis et al., 2013; Nell and Reid, 2004; Särrkä et al., 2001; Teklic et al., 2003). Consequently, a major limitation of our study is that cut flower longevity is highly variable and greatly based on the growing and postharvest handling procedures. The high variability increases retailers' risks if they post longevity information and guarantee those longevities but the product does not perform as expected.

Retailers can take several steps to use our results while minimizing their risks. First, although intuitive, retailers should continue to source their products from businesses with the best production and postharvest handling practices. As a result, the highest quality product will give consumers the greatest potential longevity for their cut flowers. Then, in the marketplace, emphasizing proper care and handling is essential to maximize cut flower longevity in the retail center and at consumers' homes (Dole and Wilkins, 1999; Nell and Reid, 2004). As such, educating staff on proper care of cut flowers from product arrival to post-sale is critical. Additionally, retailers can provide consumers with clear care instructions for their purchase(s). Furthermore, when promoting longevity, retailers need to know the performance of various products to generate accurate longevity estimates. Accurate longevity estimates can reduce the possibility of consumer dissatisfaction by setting reasonable expectations for cut flower longevity. As a result, there is a greater probability the promoted longevity is reached even if the arrangement is not in an ideal environment or care instructions are not strictly followed. Retailers can develop clear guarantee redeeming instructions and in-house procedures as well as calculate the implications of these activities. Clear instructions minimize consumer frustration. Clear procedures improve efficiency in handling situations where a guarantee is being redeemed.

One limitation of our study is we conducted our study using online surveys with consumers instead of recruiting customers while they were shopping at a floral retail outlet. Our results might have the bias common to all surveys. To test the robustness of our results, in-store trials and other experiments can be used to further explore the impact of longevity information and guarantees on consumers' purchasing decisions.

It is also important to note the experiment was conducted in July 2011. As a result of the seasonality of cut flower demand (Society of American Florists, 2005b), our results might not be applicable to other times of the year. Dennis et al. (2003) found cut flower guarantees had a low impact on consumer behavior at Valentine's Day. Future experiments can test the seasonal impacts on the importance of guarantees.

Lastly, purchasing frequency may impact the importance of longevity information and guarantees. Although sociodemographic variables were used to help explain cluster preferences, when asked for frequency of purchase, all clusters averaged two to three floral arrangements per year. Consequently, frequency of purchase was not included in the analysis. Future studies could use purchasing frequency data to further investigate the importance of longevity indicators and guarantees from the core consumer's perspective.

\section{Literature Cited}

Alfnes, F., A.G. Guttormsen, G. Steine, and K. Kolstad. 2006. Consumers' willingness to pay for the color of salmon: A choice experiment with real economic incentives. Amer. J. Agr. Econ. 88: 1050-1061

Ang, L. and B. Lee. 2000. Transacting on the Internet: A qualitative and quantitative exploration of trust, brand equity and purchase guarantee. Proc. from the ANZMAC conference, Visionary Marketing for the 21st Century: Facing the Challenge.

Behe, B.K. and S. Barton. 2000. Consumer perceptions of product and service quality attributes in six U.S. states. J. Env. Hort. 18:71-78.

Behe, B.K., T.A. Price, and H.K. Tayama. 1992. Analysis of consumer purchases of floral products in supermarkets. HortScience 27:455-459.

Bonarriva, J., C. Jabara, and S. Burket. 2003. Industry and trade summary - Cut flowers. U.S. International Trade Commission. 3 June 2013. <http:// www.usitc.gov/publications/332/pub3580.pdf>.

Chrzan, K. and B. Orme. 2000. An overview and comparison of design strategies for choicebased conjoint analysis. Sawtooth Software Research Paper Series, Sequim, WA.

Chung, J.S. and Z. Vickers. 2007. Long-term acceptability and choice of teas differing in sweetness. Food Qual. Prefer. 18:963-974.

de Gelder, I.A. 1989. Components of keeping quality used in variety evaluation. Acta Hort. 261:233-240 (ISHS). 17 Dec. 2013. <http:// www.actahort.org/books/261/261_30.htm>.

Dennis, J.H., B.K. Behe, R.T. Fernandez, R. Schutzki, T.J. Page, Jr., and R.A. Spreng. 2004. Do plant guarantees matter? The role of satisfaction and regret when guarantees are present. HortScience 40:142-145.

Dennis, J.H., B.K. Behe, R. Walden, and R.D Lineberger. 2003. Diamonds are forever... but how long do Valentine's Day roses last? SNA Res. Conf. 48:540-542.

Dole, J.M. and H.F. Wilkins. 1999. Floriculture: Principles and species. Prentice-Hall, Inc., Upper Saddle River, NJ.

Fanourakis, D., R. Pieruschka, A. Savvides, A.J. Macnish, V. Sarlikioti, and E.J. Woltering. 2013. Sources of vase life variation in cut roses: A review. Postharvest Biol. Technol. 78:1-15.

Green, S. 2011. Most commonly bought flowers. ProFlowers. 11 Mar. 2012. <http://www. proflowers.com/guide/most-commonly-boughtflowers>.

Huang, L. 2005. Floral product behaviors and their influence on consumer floral purchase frequency. HortTechnology 15:766-771.

James, J.S., B.J. Rickard, and W.J. Rossman. 2009. Product differentiation and market segmentation in applesauce: Using a choice experiment to assess the value of organic, local, and nutritional attributes. Agr. and Resource Econ. Rev. 38:357-370.

Jowkar, M.M., Z. Farshadfar, A.R. Rahmaniyan, and I.R. Iran. 2007. Predicting cut flower consumers' taste and preference for consumers' preference based selection in Shiraz, I.R. Iran. Acta Hort. 747 (ISHS)

King, R. 2007. Floral designing. Global Media, Delhi, India.

Koelemeijer, K. and H. Oppewal. 1999. Assessing the effects of assortment and ambience: A choice experimental approach. J. Retailing 75:319-345.

Kukar-Kinney, M. and R.G. Walters. 2003. Consumer perceptions of refund depth and competitive scope in price-matching guarantees: Effects on store patronage. J. Retailing 79:153-160.

Lee, K. and M.A. Khan. 2012. Exploring the impacts of service guarantee strategy. J. of Travel \& Tourism Mktg. 29:133-146.

Lessig, V.P. and J.D. Tollefson. 1971. Market segmentation through numerical taxonomy. J. of Mktg. Res. 8:480-487.

Loehlin, J.C. 1998. Latent variable models: An introduction to factor, path, and structural analysis. Lawrence Erlbaum Associates Publishers, Mahwah, NJ.

Lusk, J.L. and J.F. Shogren. 2007. Experimental auctions-Methods and applications in economic and marketing research. Cambridge University Press, New York, NY.

McDaniel, C., Jr. and R. Gates. 2010. Marketing research with SPSS. 8th Ed. John Wiley \& Sons, Inc., Hoboken, NJ.

Nagle, T.T., J.E. Hogan, and J. Zale. 2011. The strategy and tactics of pricing. Prentice Hall, Upper Saddle River, NJ.

Nell, T.A. and M.S. Reid. 2004. Special research report \#411: Postproduction. The three C's of success with fresh cut flowers (3)-'Care.' American Floral Endowment. 12 Dec. 2013. $<$ http://endowment.org/images/stories/research/ Research_Post_Production/411postprod.pdf $>$.

Oppenheim, P. 2000. Segmentation and target marketing in a floral market. ISHS or Acta Hort. 529-536.

Ortony, A., G.L. Clore, and A. Collins. 1988. The cognitive structure of emotions. Cambridge University Press, Cambridge, UK.

Ozzambak, M.E., E. Zeybekoglu, O. Tuncay, S. Baser, G. Haspolat, and A. Olgun. 2009. A survey on cut flower preferences and expectations. Proc. IS on Prot. Cult. Mild Winter Climate; Acta Hort. 807, ISHS.

Regan, E.M., J.M. Dole, and I.F. McCall. 2007. Special research report \#440: Postproduction. Evaluating the vase life of new cut flower cultivars-Year 2 (2007). American Floral Endowment. 15 Dec. 2013. <http://endowment. org/images/stories/research/Research_Post_ Production/440dole.pdf $>$.

Regan, E.M., J.M. Dole, E.Y. Moody, and I.F. McCall. 2006. Special research report \#439: Postproduction. Evaluating the vase life of new cut flower cultivars-Year 1 (2006). American Floral Endowment. 15 Dec. 2013. $<$ http://endowment.org/images/stories/research/ Research Post Production/439dole.pdf $>$.

Regan, E.M., J.M. Dole, E.Y. Moody, and I.F. McCall. 2008. Special research report \#441: Postproduction. Evaluating the vase life of new cut flower cultivars-Year 3 (2008). American Floral Endowment. 15 Dec. 2013. <http:// endowment.org/images/stories/research/ Research_Post_Production/441dole.pdf $>$.

Rihn, A.L., C. Yue, B.K. Behe, and C. Hall. 2011. Generations $\mathrm{X}$ and $\mathrm{Y}$ attitudes toward fresh flowers as gifts: Implications for the floral industry. HortScience 46:736-743. 
Roster, C.A. 2006. Moments of truth in gift exchanges: A critical incident analysis of communication indicators used to detect gift failure. Psychology \& Mktg. 23:885-903.

Särrkä, L.E., H.J. Rita, and S.O. Ripatti. 2001. Cut rose flower longevity and its variation between plants of cv. Frisco grown in different lighting periods. Acta Hort. 547:255-260 (ISHS). 15 Dec. 2013. <http://www.actahort.org/books/ 547/547_31.htm>.

Schiffman, L.G. and L.L. Kanuk. 2007. Consumer behavior. 9th Ed. Pearson Education Inc., Upper Saddle River, NJ.

Smith, C.N. 1968. A study of consumer opinions and practices about flowers and flowering plants. Florida Ag. Exp. Station J. Series. p. 368-375.

Society of American Florists. 2005a. Meet today's floral consumer. 3 June 2013. <http://safcms. memberfuse.com/node/201>.
Society of American Florists. 2005b. Consumer buying trends. 3 June 2013. <http://www. aboutflowers.com/about-the-flower-industry/ consumer-trends.html>.

Society of American Florists. 2013. Flower industry overview. 3 June 2013. <http://www. aboutflowers.com/about-the-flower-industry/ industry-overview.html $>$.

Tavakol, M. and R. Dennick. 2011. Making sense of Cronbach's alpha. International J. of Medical Edu. 2:53-55.

Teklic, T., N. Paradzikovic, and V. Vukadinovic. 2003. The influence of temperature on flower opening, vase life and transpiration of cut roses and carnations. Acta Hort. 624:405-411 (ISHS). 17 Dec. 2013. <http://www.actahort.org/books/ 624/624_57.htm>.

Train, K. 2003. Discrete choice methods with simulation. Cambridge University Press, Cambridge, UK.
U.S. Census Bureau. 2013. People and households. 12 Dec. 2013. <http://www.census.gov/people/>. Ward, J.E., Jr. 1963. Hierarchical grouping to optimize an objective function. J. Am. Stat. Assoc. 59:236-244.

Yue, C., H.H. Jensen, D.S. Mueller, G.R. Nonnecke, D. Bonnet, and M.L. Gleason. 2007. Estimating consumers' valuation of organic and cosmetically damaged apples. HortScience 42:13661371.

Yue, C., A.L. Rihn, B.K. Behe, and C. Hall. 2009. Consumer preference for flowers as gifts: Age segments, substitutes, and perceived risk. American Floral Endowment. 11 Dec. 2011. <http:// www.maumeevalleygrowers.com/documents/ ConsumerPrefRptFloral.pdf $>$.

Zarantonello, L. and B.H. Schmitt. 2010. Using the brand experience scale to profile consumers and predict consumer behavior. J. of Brand Mgt. 17:532-540. 